\title{
Comparison of ST segment Changes in Lead aVR with in-Hospital Outcomes in Patients with First attack of Acute Inferior ST Segment Elevation Myocardial Infarction
}

\author{
Mohammad Jalal Uddin ${ }^{1}$, M. Saiful Bari ${ }^{1}$, M.A. Bari ${ }^{1}$, Mirza Md. Nazrul Islam ${ }^{1}$, M. Abdullah-Al-Safi \\ Majumder², Zahidul Islam¹, Gana Pati Aditya ${ }^{1}$, Gobinda Kanti Paul ${ }^{1}$, Rakhal Chandra Debnath ${ }^{1}$, \\ Shahriar Iqbal ${ }^{1}$, Md. Shamim Chowdhury ${ }^{3}$, Md. Saidur Rahman ${ }^{1}$ \\ ${ }^{1}$ Department of Cardiology, Mymensingh Medical College, Mymensingh, ${ }^{2}$ National Institute of \\ Cardiovascular Diseases, Dhaka, ${ }^{3}$ National Heart Foundation, Dhaka
}

Key words:

Ischaemic heart

disease, STEMI, lead aVR, ECG.

\begin{abstract}
Background: Inferior wall ST segment elevation myocardial infarction is considered to be at lower risk than anterior wall STEMI except in some cases. The aim of our study was to evaluate the relationships between on admission ST segment changes in lead aVR and short term in-hospital outcomes in acute isolated inferior myocardial infarction undergoing thrombolysis.

Methods: Total 107 of first attack of inferior STEMI patients were included and all were thrombolysed by streptokinase. The sample population were divided into three groups based on the condition of ST segment in lead aVR on admission and in hospital outcomes were observed: Group $-A$ : ST segment elevation $\geq 0.5 \mathrm{~mm}$; Group $-B$ : ST segment depression $\geq 0.5 \mathrm{~mm}$; Group-C : Iso-electric ST segment.

Results: $6.54 \%$ of study population had ST segment elevation in lead aVR, 53.27\% had ST segment depression in lead aVR and $41.12 \%$ had isoelectric ST segment in lead aVR. During hospital stay mortality rates of patients of Group A, Group B and Group C were $33.3 \%, 5.3 \%$ and $4.5 \%$ respectively; rates of cardiogenic shock were $33.3 \%, 8.8 \%$ and $2.3 \%$ respectively; heart failure rates were $50.0 \%, 15.8 \%$ and $4.5 \%$ respectively; rates of recurrent angina after thrombolysis were $66.7 \%, 33.3 \%$ and $6.8 \%$ respectively in three groups and the mean LVEF were 40.17, 48.61 and 52.50 respectively.

Conclusion: The on admission-isoelectric ST segment in lead aVR in acute inferior myocardial infarction predicted better in-hospital outcomes in comparison to ST segment elevation and ST segment depression in aVR. On the other hand, ST segment elevation in lead aVR predicted worse in-hospital outcomes than ST segment depression in acute inferior myocardial infarction in spite of reperfusion by thrombolytic.
\end{abstract}

(Cardiovasc. j. 2019; 11(2): 123-128)

\section{Introduction:}

Acute coronary syndrome (ACS) is an emergencyrequiring immediate diagnosis and treatment. It is increasing in developed as well as in developing countries like ours. In spite of modern treatment the rate of death due to ACS still remains high. Early diagnosis and management can save significant number of lives. ${ }^{1}$

The accurate diagnosis of ST elevation myocardial infarction (STEMI) is of paramount importance; as the diagnosis mandates immediate consideration for reperfusion therapy, either by thrombolytic agents or by mechanical revascularization, most probably PCI. Mortality has been significantly decreased by reperfusion within 12 hours of onset of symptoms in patients with STEMI. ${ }^{2}$

ST segment elevation myocardial infarction (STEMI) of the inferior wall is considered to be associated with a lower risk of MI than STEMI of anterior wall. Nevertheless, approximately 30\% of patients with inferior wall STEMI experience complications during their hospital stay which are associated with poor prognosis. ${ }^{3-6}$

Address of Correspondence: Dr. Mohammad Jalal Uddin, Department of Cardiology, Mymensingh Medical College, Mymensingh, Bangladesh. Email-dr. jalalm32@gmail.com

(C) 2018 authors; licensed and published by International Society of Cardiovascular Ultrasound, Bangladesh Chapter and Bangladesh Society of Geriatric Cardiology. This is an Open Access article distributed under the terms of the CC BY NC 4.0 (https:// creativecommons.org/licenses/by-nc/4.0). 
The 12-lead electrocardiogram (ECG) is a crucial tool in the diagnosis and risk stratification of acute coronary syndrome (ACS). Unlike other 11 leads, lead aVR has been long neglected until recent years. However, recent investigations have shown that an analysis of ST-segment shift in lead aVR provides useful information on the coronary angiographic anatomy and risk stratification in ACS. ST-segment elevation in lead aVR can be caused by (1) transmural ischemia in the basal part of the interventricular septum caused by impaired coronary blood flow of the first major branch originating from the left anterior descending coronary artery; (2) transmural ischemia in the right ventricular outflow tract caused by impaired coronary blood flow of the large conal branch originating from the right coronary artery; and (3) reciprocal changes opposite to ischemic or non-ischemic STsegment depression in the lateral limb and precordial leads. On the other hand, ST-segment depression in lead aVR can be caused by transmural ischemia in the inferolateral and apical regions. It has been recently shown that an analysis of $\mathrm{T}$ wave in lead aVR also provides useful prognostic information in the general population and patients with prior myocardial infarction. Cardiologists should pay more attention to the tracing of lead aVR when interpreting the 12-lead ECG in clinical practice. ${ }^{7}$

Lead aVR may be considered to be orientated to or face the heart from the right shoulder. This lead is usually orientated to the cavity of the heart. Since lead aVR is directed towards the cavity of the heart, all the vectors -both atrial and ventricular -are directed away from this lead, which will consequently normally reflect all the negative deflections. The $\mathrm{P}$ wave, the QRS complex, and the $\mathrm{T}$ wave will thus normally all be negative. ${ }^{8}$

\section{Methods:}

Study population :The cross sectional prospective analytical Study was carried out in the Department of Cardiology, Mymensingh Medical college Hospital, Mymensingh, Bangladesh from December-2016 to November - 2017 (12 months) on consecutive 107 patients of first attack of acute inferior myocardial infarction admitted to the coronary care unit . All the cases were selected by purposive convenient sampling. The sample population was divided into three groups (aVR groups)on the basis of ST segment changes on lead aVR on admission: Group -A ( $\mathrm{n}=6$, male-6): Patients with ST elevation in aVR ; Group $-\mathrm{B}(\mathrm{n}=57$; male51; female-6) : Patients with ST depression in aVR ; and Group-C(n=44; male-44; female-6) : Patients with isoelectric ST segment in aVR on admission. Group-C was control group. As inhospital outcomes complications (mortality, cardiogenic shock, heart failure and recurrent angina) of patients and LVEF were recorded according to aVR groups during the period of hospital stay in coronary care unit. Inclusion Criteria: Patients with first attack of isolated inferior ST elevation myocardial infarction within 12 hours of onset of chest pain undergoing thrombolysis. Exclusion Criteria : Old myocardial infarction, infarction of other walls, valvular heart disease, congenital heart disease and cardiomyopathy, major non cardiovascular disorder such as severe renal impairment, major surgery, chest trauma, myocarditis, pericarditis, acute pulmonary embolism, any systemic infection, Patients under chemotherapy for malignancy and patients do not willing to enroll in study.

ECG analysis: The first ECG was analyzed at a paper speed of $25 \mathrm{~mm} / \mathrm{s}$ with standard calibration and the time from onset of chest pain to ECG changes was recorded for diagnosis of inferior STEMI. ST segment changes (elevation and depression) in lead aVR on admission were measured manually at $60 \mathrm{~ms}$ after the $\mathrm{J}$ point, and a magnitude of $0.5 \mathrm{~mm}$ was considered significant. The magnitude of ST segment changes in lead aVR was relative to the TP segment as a baseline. The characteristics of ST segment changes in the II, III, aVF, and aVR leads were analyzed. ${ }^{10}$ The patients were divided in three aVR groups according to the characteristics of ST segment in lead aVR on admission-Group -A : ST segment elevation(at least $60 \mathrm{~ms}$ from $J$ point) $0.5 \mathrm{~mm}$ from T-P segment; Group -B : ST segment depression(at least $60 \mathrm{~ms}$ from $\mathrm{J}$ point) $0.5 \mathrm{~mm}$ from T-P segment;Group-C : Isoelectric ST segment (at least $60 \mathrm{~ms}$ from $\mathrm{J}$ point) $<0.5 \mathrm{~mm}$ from T-P segment.

Statistical Methods: The collected data were processed and analyzed with the aid of computer software SPSS (Statistical package for social science) Version 20. Level of significance was 
considered as p value less than 0.05 ( $p<$ 0.05).Quantitative data were expressed as mean \pm SD and ANOVA test was employed for analysis. Qualitative data were analyzed with $\chi^{2}$ test. Comparison among groups was made by ANOVA test for quantitative data.

\section{Results:}

One hundred seven (107) patients with inferior myocardial infarction were included in the present study. Patients were divided into three groups according to the presence of ST segment elevation, ST segment depression and isoelectric ST segment in lead aVR with first attack of acute inferior ST elevation myocardial infarction on admission and who all were illegible for thrombolysis by streptokinase therapy. Group A: 6 patients (with ST segment elevation $\geq 0.5$ mm in lead aVR) Group B: 57 patients (with ST segment depression $\geq 0.5 \mathrm{~mm}$ in lead aVR) Group C: 44 patients (with isoelectric ST segment $<0.5$ $\mathrm{mm}$ in lead aVR)
In our study among 107 cases, 6.54\% showed ST segment elevation in lead aVR, 53.27\% ST segment depression in lead aVR and $41.12 \%$ isoelectric ST segment in lead aVR. Mean age of the patients was $55.83 \pm 15.30$ years in Group-A (ST segment elevation in lead aVR), $57.47 \pm 11.55$ years in Group-B patients (ST segment depression in lead aVR) and 55.00 \pm 11.04 years in Group-C patients (isoelectric ST segment in lead aVR). In our study, out of 107 cases 95 were male and 12 were female, among them $6(100.0 \%)$ male and 0 female were in Group-A, 51(89.5\%) male and $6(10.5 \%)$ female were in Group-B and $38(86.4 \%)$ male and $6(13.6 \%)$ female were in Group-C. Male-female ratio was 7.91:1. As in-hospital outcomes the mortality rates of patients of Group A, Group B and Group C were $33.3 \%, 5.3 \%$ and $4.5 \%$ respectively; rates of cardiogenic shock were $33.3 \%, 8.8 \%$ and $2.3 \%$ respectively; heart failure rates were $50.0 \%$, $15.8 \%$ and $4.5 \%$ respectively; rates of recurrent angina after thrombolysis were $66.7 \%, 33.3 \%$ and

\section{Table-I}

Age distribution of the study population ( $N=107)$.

\begin{tabular}{|c|c|c|c|c|c|c|c|}
\hline & \multicolumn{2}{|c|}{ Group-A $(\mathrm{n}=6)$} & \multicolumn{2}{|c|}{ Group-B $(\mathrm{n}=57)$} & \multicolumn{2}{|c|}{ Group-C $(\mathrm{n}=44)$} & \multirow[t]{2}{*}{$\mathrm{p}$ value } \\
\hline & $\overline{\text { Count }}$ & $\%$ & Count & $\%$ & Count & $\%$ & \\
\hline$<35$ & 0 & 0.0 & 2 & 3.5 & 3 & 6.8 & \\
\hline $36-45$ & 2 & 33.3 & 6 & 10.5 & 6 & 13.6 & \\
\hline $46-55$ & 2 & 33.3 & 20 & 35.1 & 16 & 36.4 & \\
\hline $56-65$ & 1 & 16.7 & 18 & 31.6 & 14 & 31.8 & \\
\hline $66-75$ & 0 & 0.0 & 7 & 12.3 & 4 & 9.1 & \\
\hline $76-85$ & 1 & 16.7 & 3 & 5.3 & 1 & 2.3 & \\
\hline$>85$ & 0 & 0.0 & 1 & 1.8 & 0 & 0.0 & \\
\hline Total & 6 & 100.0 & 57 & 100.0 & 44 & 100.0 & \\
\hline Mean \pm SD & \multicolumn{2}{|c|}{$55.83 \pm 15.30$} & \multicolumn{2}{|c|}{$57.47 \pm 11.55$} & \multicolumn{2}{|c|}{$55.00 \pm 11.04$} & $0.564^{\mathrm{NS}}$ \\
\hline
\end{tabular}

NS means not-significant $(\mathrm{p}>0.05)$

Table-II

Clinical and demographic characteristics of study population $(N=107)$.

\begin{tabular}{|c|c|c|c|c|c|c|c|c|}
\hline & & & \multicolumn{4}{|c|}{ Group } & \multicolumn{2}{|c|}{ Total(N=107) } \\
\hline & \multicolumn{2}{|c|}{ Group-A $(\mathrm{n}=6)$} & \multicolumn{2}{|c|}{ Group-B $(\mathrm{n}=57)$} & \multicolumn{2}{|c|}{ Group- $\mathrm{C}(\mathrm{n}=44)$} & \multirow[b]{2}{*}{ Count } & \multirow[b]{2}{*}{$\%$} \\
\hline & Count & $\%$ & Count & $\%$ & Count & $\%$ & & \\
\hline$\overline{\text { Sex (male) }}$ & 6 & 100.0 & 51 & 89.5 & 38 & 86.4 & 95 & 88.8 \\
\hline Smoking & 5 & 83.3 & 49 & 86.0 & 36 & 81.8 & 90 & 84.1 \\
\hline HTN & 2 & 33.3 & 26 & 45.6 & 19 & 43.2 & 47 & 43.9 \\
\hline $\mathrm{DM}$ & 3 & 50.0 & 13 & 22.8 & 9 & 20.5 & 25 & 23.4 \\
\hline Dyslipidemia & 0 & 0.0 & 0 & 0.0 & 3 & 6.8 & 3 & 2.8 \\
\hline $\begin{array}{l}\text { Family history } \\
\text { of CAD }\end{array}$ & 1 & 16.7 & 16 & 28.1 & 18 & 40.9 & 35 & 32.7 \\
\hline
\end{tabular}


Table III

In-hospital outcome in study population $(N=107)$.

\begin{tabular}{|c|c|c|c|c|c|c|c|c|c|}
\hline & \multicolumn{2}{|c|}{ Group-A (n=6) } & \multicolumn{2}{|c|}{ Group-B (n=57) } & \multicolumn{2}{|c|}{ Group-C (n=44) } & \multicolumn{2}{|c|}{ Total $(\mathrm{N}=107)$} & \multirow[t]{2}{*}{$p$ value } \\
\hline & Count & $\%$ & Count & $\%$ & Count & $\%$ & Count & $\%$ & \\
\hline Death & 2 & 33.3 & 3 & 5.3 & 2 & 4.5 & 7 & 6.5 & $0.024^{*}$ \\
\hline Cardiogenic shoc & k 2 & 33.3 & 5 & 8.8 & 1 & 2.3 & 8 & 7.5 & $0.022 *$ \\
\hline Heart failure & 3 & 50.0 & 9 & 15.8 & 2 & 4.5 & 14 & 13.1 & $0.006 *$ \\
\hline Recurrent angina & a 4 & 66.7 & 19 & 33.3 & 3 & 6.8 & 26 & 24.3 & $0.001 *$ \\
\hline LVEF & 40.17 & 1.33 & 48.61 & 8.64 & 52.50 & 7.50 & 49.74 & 8.45 & $0.002^{*}$ \\
\hline
\end{tabular}

* means significant at $5 \%$ level $(\mathrm{p}<0.05)$ by chi-square test $(\mathrm{p}$ value- 0.024$)$

$6.8 \%$ respectively in three groups and the mean LVEF were 40.17, 48.61 and 52.50 respectively.

\section{Discussion:}

The present study found that among 107 cases, $6.54 \%$ showed ST segment elevation in lead aVR, $53.27 \%$ ST segment depression in lead aVR and $41.12 \%$ isoelectric ST segment in lead aVR. A study, reported $9.4 \%$ ST segment elevation in lead aVR, 35.4\% ST segment depression in lead aVR and $55.2 \%$ isoelectric ST segment in lead aVR among 96 patients. ${ }^{10}$

Age is an important predictor of survival after acute myocardial infarction. ${ }^{11}$ Mean age of the present study was $55.83 \pm 15.30$ years in Group-A (ST segment elevation in lead aVR), $57.47 \pm 11.55$ years in Group-B patients (ST segment depression in lead aVR) and 55.00土11.04 years in Group-C patients (isoelectric ST segment in lead aVR). The majority of patients were in the age range of 36-55 years in Group-A, 46-65 years in Group-B and in Group-C. But $33.3 \%$ patients were in $36-45$ years and $33.3 \%$ were in $46-55$ years in Group-A and $35.1 \%$ patients in $46-55$ years in Group-B and $36.4 \%$ in 46-55 years in Group-C. Analysis revealed statistically non-Significant difference $(p=0.564)$. On the other hand, a study showed the mean age of $62.7+\_12.3$ years which was statistically non significant similar to the present study. ${ }^{10}$

In our study, out of 107 cases 95 were male and 12 were female, among them $6(100.0 \%)$ male and 0 female were in Group-A, 51(89.5\%) male and $6(10.5 \%)$ female were in Group-B and 38 (86.4\%) male and $6(13.6 \%)$ female were in Group-C which was statistically non significant $(p=0.593)$. Male-female ratio was 7.91:1. In a study done found 77 males and 19 females out of total 96 cases and male-female ratio was 4.05:1. So, like other studies, males were predominant in our study. ${ }^{10}$
In our study, we found that the in-hospital mortality rates of patients of Group A, Group B and Group C were 33.3\%, 5.3\% and $4.5 \%$ respectively $(\mathrm{p}=0.024)$ which was statistically significant and highest mortality was in group A. On the other hand, a study, reported that the in-hospital mortality rates of patients with ST segment elevation, ST segment depression, and no ST segment changes in lead aVR were $27.7 \%, 16.5 \%$, and $1.0 \%$, respectively ( $<<0.001$ ) which was also statistically significant and highest mortality was in ST elevation group which was similar with our result. ${ }^{10}$

The present study showed that during hospital stay composite end-point rates of cardiogenic shock among three groups were $33.3 \%, 8.8 \%$ and $2.3 \%$ respectively $(\mathrm{p}=0.022)$ which was statistically significant and were highest in group A. Whereas, a study reported that the percentage of patients with ST segment elevation, ST segment depression, and with no ST segment change who reached the composite end-point (death or cardiogenic shock) was $31.9 \%, 27.0 \%$, and $3.2 \%$, respectively $(\mathrm{p}<0.001)$ which was also statistically significant and highest rate of cardiogenic shock developed in ST elevation group which was similar with our study. ${ }^{10}$

A study stated that left ventricular dysfunction is the single most important predictor of mortality following STEMI. In patients with STEMI, either systolic dysfunction alone or both systolic and diastolic dysfunction can occur. ${ }^{12}$ Left ventricular diastolic dysfunction leads to pulmonary venous hypertension and pulmonary congestion. Our study showed that during hospitalization heart failure rates were $50.0 \%$, $15.8 \%$ and $4.5 \%$ among Group A, Group B and 
Group C respectively $(\mathrm{p}=0.006)$ which was statistically significant and Group A was the highest heart failure group. In contrast, a study reported that congestive cardiac failure developed $21.4 \%$ in $\mathrm{ST}$ segment depression group and $20.0 \%$ in ST segment depression absent group in acute myocardial infarction which was also statistically significant and this study was not done on ST elevation in lead aVR group of patient. ${ }^{13}$ Another study reported that in anterolateral AMI undergoing successful reperfusion during hospitalization, congestive heart failure occurred more frequently in group $\mathrm{C}$ (patients with ST depression of $>$ or $=0.5 \mathrm{~mm}$ ) than in groups A (patients with ST elevation of $\geq 0.5 \mathrm{~mm}$ ) or B (patients without ST deviation) $(\mathrm{p}<.05) .{ }^{14}$

The present study showed that during hospitalization rates of recurrent angina after thrombolysis were $66.7 \%, 33.3 \%$ and $6.8 \%$ respectively ( $\mathrm{p} .001)$ among three groups which was statistically significant and highest rate of recurrent angina was on group A. Whereas, a study reported that post infarct angina developed $21.4 \%$ in ST segment depression group and $20.0 \%$ in ST segment depression absent group in acute myocardial infarction which was also statistically significant. ${ }^{13}$

Ejection fraction is the most commonly used index of LV function and it also differentiates patients with and without a complicated inhospital clinical course. ${ }^{15}$ In our study, all patients of Group A, Group B and Group C were screened out by predischarge transthoracic echocardiography to see LVEF and found the mean values- 40.17, 48.61 and 52.50 respectively $(\mathrm{p}=0.002)$ which was statistically significant and lowest EF was found in group A. overall LVEF among three groups was $47 \%$. A study showed mean left ventricular ejection fraction was $54.9 \pm 8.6 \%$ on overall inferior STEMI patients who were thrombolysed. ${ }^{10}$ Another study showed mean left ventricular ejection fraction of patients treated with PCI were in Group B and Group C $53.7 \pm 8.7$ and $59.2 \pm 7.8$ respectively but not studied about Group A. ${ }^{15}$ An experiment showed the relation between ST-segment deviation in lead aVR on admission ECG and left ventricular function in 105 patients with an anterolateral AMI undergoing successful reperfusion $\leq 6$ hours after onset. ${ }^{14}$ Patients were classified according to ST-segment deviation in lead aVR on admission ECG: group A, 23 patients with ST elevation of $\geq 0.5 \mathrm{~mm}$; group B, 47 patients without ST deviation; and group C, 35 patients with ST depression of $\geq 0.5 \mathrm{~mm}$. A study showed that the LVEF measured by predischarge left ventriculography was $54 \% \pm 9 \%, 48 \% \pm 7 \%$, and $37 \% \pm 9 \%$, respectively $(\mathrm{p}<.01)$ and ST-segment depression in lead aVR had a higher predictive accuracy than other ECG findings in identifying patients with predischarge LVEF $\leq 35 \%$. But our study showed the lowest mean LV ejection fraction in group A. ${ }^{14}$

From the above discussion we found that in patients with first attack of acute inferior ST segment elevation myocardial infarction, ST segment changes mainly ST elevation in lead aVR markedly influenced in-hospital outcomes.

\section{Limitations of the study}

This study was not without limitations. The limitations of the study were as follows:

- Sample size was small

- This study was conducted in only one center.

- Anatomical correlation of infarct related artery was not done by coronary angiogram.

\section{Conclusion:}

On this study the on admission isoelectric ST segment in lead aVR in acute inferior myocardial infarction predicted better in-hospital outcomes in comparison to ST segment elevation and ST segment depression in aVR. On the other hand, ST segment elevation in lead aVR predicted worse in-hospital outcomes than ST segment depression in acute inferior myocardial infarction in spite of reperfusion by thrombolytic

Conflict of Interest - None.

\section{References:}

1. Acute Coronary Syndrome-Guide line for Management. Dhaka: Asian Colour Printing. Bangladesh Cardiac Society. 2004.

2. Kim MC, Kini AS, Fuster V. Definitions of Acute Coronary Syndromes. In: Fuster V, Walsh RA, Harrington RA. Eds. 
Hurst's The Heart. $13^{\text {th }}$ edition. New York: McGraw-Hill, 2011: 1287-1294.

3. Berger PR, Ryan TJ. Inferior myocardial infarction — high risk subgroups. Circulation 1990; 81: 401-411.

4. Erhardt LR, Sjogen A, Walberg L. Single right-sided precordial lead in the diagnosis of right ventricular involvement in inferior myocardial infarction. Am Heart $J$ 1976; 91: 671-678.

5. Kukla P, Dudek D, Rakowski T. Inferior wall myocardial infarction with or without right ventricular involvementtreatment and in-hospital course. Kardiol Pol 2006; 64: $583-588$.

6. Gumina RJ, Wright RS, Kopecky SL. Strong predictive value of TIMI risk score analysis for in-hospital and longterm survival of patients with right ventricular infarction. Eur Heart J 2002; 23: 1678-1683.

7. Tamura A. Significance of lead aVR in acute coronary syndrome. World J Cardiol 2014; 6(7): 630-637.

8. Selvara R. The Electrical axis. In: Narasimhan C, Francis J. Eds. Leo Schamroth- An Introduction to Electrocardiography. $8^{\text {th }}$ edition. New Delhi: Wiley India, 2013: 22 - 27.

9. Bohora S. Principles of Electrocardiographic changes in Coronary artery disease. In: Narasimhan C, Francis J. Eds. Leo Schamroth- An Introduction to Electrocardiography, $8^{\text {th }}$ edition. New Delhi: Wiley India, 2013: 67-71..
10. Kukla, P, Bryniarski L, Dudek D, Królikowski K, Jaszcz KK. Prognostic significance of ST segment changes in lead aVR in patients with acute inferior myocardial infarction with ST segment elevation. Kardiol Pol 2012; 70( 2): 111118

11. Barakat K, Wilkinson P, Deaner K. How should age affect management of acute myocardial infarction? A prospective cohort study. Lancet 1999; 353: 955-959.

12. Scirica BM, Morrow DA. ST-Elevation Myocardial Infarction: Pathology, Pathophysiology, and Clinical Features. In: Mann DL, Zipes DP, Libby P, Bonow RO. Eds. Braunwald's Heart Disease: A Textbook of Cardiovascular Medicine. 10th Edition. Philadelphia: Elsevier, 2015: 1069

13. Senaratne MP., Weerasinghe C, Smith G, Mooney D. Clinical Utility of ST segment depression in lead aVR in acute myocardial infarction. J Electrocardiol 2003:11-16.

14. Kosuge M, Kimura K, Ishikawa T. ST-segment depression in lead aVR predicts predischarge left ventricular dysfunction in patients with reperfused anterior acute myocardial infarction with anterolateral STsegment elevation. Am Heart J 2001; 142(1):51-57.

15. Ascione R, Narayan P, Rogers CA. Early and Mid term clinical outcome in patients with severe left ventricular dysfunction undergoing coronary artery surgery. Ann Thoracic Surg 2003; 76: 793-799. 